\title{
Decitabine Regimen
}

National Cancer Institute

\section{Source}

National Cancer Institute. Decitabine Regimen. NCI Thesaurus. Code C160021.

A chemotherapy regimen consisting of decitabine that may be used in the treatment of acute myeloid leukemia (AML), myeloproliferative neoplasms, and myelodysplastic syndromes. 